\title{
Green Exercise and Rural America: Cultural, Ecological, and Ideological Implications for Positive Social Change
}

\author{
Joshua M. Garrin \\ Walden University
}

\begin{abstract}
As the global obesity pandemic continues to extend its epidemiological reach, its magnitude continues to transcend demographic boundaries. Increasingly, the extant literature highlights the myriad challenges experienced by socioeconomically disenfranchised populations to combat the insidious biopsychosocial impact of chronic health conditions. However, a counter argument suggests that rural Americans have wide ranging access to the natural environment-an intrinsic resource that offers a broad spectrum of health and wellness opportunities. Beyond its application as a tool for good health practices, green exercise-defined as physical activity in natural settings—can provide an existential platform for the ideals of self-sufficiency, solidarity, and sustainability. A call to capitalize on pre-existing prohealth resources represents an open window for social change dialogue as participants learn to reframe the idea of exercise-not as a task demand, but as an internalized lifestyle value. Invoking Astin and Astin's (1996) social change model of leadership development, mentors of green exercise programs have opportunities to optimize their leadership and coalition skills, engender diversity-positive attitudes, and affect positive change in a widely underserved population. The following discussion highlights (a) cultural and ideological considerations, (b) theoretical foundations, (c) virtues of social change agency, and (d) the critical role of the program mentor as a facilitator of positive social change in the green exercise milieu. For a population that has been historically entrenched in perceived limitations, a revisionist view suggests that rural Americans have an abundance of naturebased prohealth resources at their disposal. Green exercise initiatives not only represent a practical health platform for rural Americans, but such opportunities can have a transformative impact on the timeworn socioecological dynamics that mediate positive social change.
\end{abstract}

Keywords: green exercise, health, mentorship, rural Americans, social change

\section{Introduction}

Global epidemiology and disease prevention research elucidates health management as a biopsychosocially complex phenomenon (World Health Organization [WHO], 2014). Cardiovascular disease, the leading cause of death worldwide (American Heart Association, 2014), has been linked to comorbid obesity, cancer, Type II diabetes, stroke, and lifestyle-specific risk factors that have been correlated to hypertensive disease (Centers for Disease Control and Prevention [CDC], 2013a; Santulli, 2013). Similarly, current epidemiological data reveal demographic disparities in the obesity epidemic; currently, $65 \%$ of the global populace resides in locales where weight-related fatalities outpace those due to clinically underweight conditions-a figure that has doubled in the past 3 decades (WHO, 2014). 
In addition, the CDC (2013a) reported a marked upward trend in obesity and overweight statistics in the United States in the past 20 years: Current data shows obesity prevalence rates of $25 \%$ to $<30 \%$ in 23 states and $30 \%$ to $<35 \%$ in 18 states (CDC, 2013a). As compared to White individuals, evidence shows a $>50 \%$ higher obesity prevalence in African American and a $21 \%$ higher prevalence in Hispanic individuals - with dramatically higher prevalence rates $(+30 \%)$ reported for rural Americans of all ethnic affiliations in the southern United States (CDC, 2013a). Further, current data shows individuals diagnosed with chronic health conditions to be paying over $40 \%$ more in healthcare expenditures than otherwise healthy individuals (CDC, 2013b; Finkelstein, Trogdon, Cohen, \& Dietz, 2009). With a dramatically higher disease chronicity prevalence observed in rural Americans as compared to their urban counterparts (Lutfiyya et al., 2013), such findings have potential implications for the broad impact of chronic health conditions on socioeconomically challenged populations.

Despite the modifiable and ultimately preventable nature of many metabolic health conditions, the U.S. obesity trajectory has largely remained unchanged since 2011 (CDC, 2013a; Ogden, Carroll, Kit, \& Flegal, 2014; WHO, 2014). As such, there is an ever increasing need for practical, noninvasive methodologies for indoctrinating prohealth ideals in rural populations-a cohort for which the risk trajectory is predicted to increase and prevalence rates are currently among the highest for obesity, cardiovascular disease, and comorbid health conditions in the United States (CDC, 2013a; Lutfiyya, Chang, \& Lipsky, 2012; Thorp, Owen, Neuhaus, \& Dunstan, 2011). The following discussion examines the ecological factors, theoretical foundations, ideological virtues, and mentorship values that dynamically impact health value adoption in rural Americans. Perspectives highlight the value of nature-based health behavior change initiatives for rural Americans and their potentially transformative ecological impact on social change agency.

\section{Exercise and Rural Americans: Cultural, Ecological, and Ideological Implications for Health Behavior}

Engstrom (2004) purported that humans innately seek to conserve energy and avoid volitional engagement in energy expending behavior unless such activities serve to satisfy basic needs. Despite the volitional capacity of humans to walk, run, climb, and engage in various other movement-based activities (Owen, Sparling, Healy, Dunstan, \& Matthews, 2010), functionalist views (Durkheim, 1924) suggest that the choice to engage in specific behaviors may be based upon the collective perception of whether such behaviors are perceived to serve a physical, psychological, or interpersonal purpose. Here, culturally grounded social learning ideals are indoctrinated within the social schema and, thus, have an internalizing impact on beliefs and behavior (Bandura, 1977b). As intergenerationally transmitted attitudes and values are communicated within the family constellation (Dickson, McCarthy, Howe, Schipper, \& Katz, 2013; Rimal, 2003), the phenomenology of culture becomes a critical consideration when attempting to transform the perceptions that perpetuate belief systems.

The cultural mechanisms that drive health behavior were explained in part by Parsons (1966), who posited that deeply embedded beliefs within cultural systems have served to reinforce social order throughout successive generations. Here, the collective avoidance of or engagement in specific behaviors by a group serves to maintain social equilibrium (Parsons, 1966). When the idea of health is viewed not as not a cluster of behaviors to be practiced, but as a core value that can be internalized (Springer, Lamborn, \& Pollard, 2013), two fundamentally important views emerge: (a) the choice to engage in exercise is a socially learned and culturally guided phenomenon, and 
(b) exercise behavior must in some capacity contribute to the continued homeostasis or evolution of the system (Parsons, 1966).

The beliefs that underpin health behavior often influence perceived susceptibility to health conditions and perceived vulnerability to the consequences of illness (Rosenstock, Strecher, \& Becker, 1988). If rural residents believe that they will inevitably die of a specific event, the prospect of chronic health conditions could fail to pose an exigent threat to their livelihood; despite the potential limitations imposed by specific conditions, they may still be able to earn a living, engage in social relations, and undertake daily functional activities (Rosenstock et al., 1988). Evidence shows that when compared to urban residents, rural residents demonstrate a significantly greater tendency to engage in health risk taking behavior (Logan, Guo, Dodd, Muller, \& Riley, 2013). Despite the everpresent need for many rural Americans to consider more adaptive health practices, the degree of contemplation, planning, and action required to modify behavior underscores the psychosocial complexity of the change process (Prochaska, Redding, \& Evers, 2008).

\section{Health Motivation in Rural Americans: Theoretical Implications}

In an effort to better understand the health behavior of rural Americans, the following section highlights several theories that have biological, psychological, and social relevance to the motivations that underlie health behavior change.

\section{Biopsychological Theories}

Research shows indiscriminate, dysregulated eating behavior to occur as a result of a neurochemical conditioning process (Liu, von Deneen, Kobeissy, \& Gold, 2010; Orford, 1985; Orford, Morison, \& Somers, 1996). System dysregulation, behavioral discontrol, and an unmitigated psychophysiological craving of the food stimulus have been correlated to individuals who lack access to community support resources (Amedeo et al., 2011; Kalivas, 2003). Similarly, research on energy balance shows that weight homeostasis is achieved when caloric intake equals caloric expenditure (Dabney, 1964). Given the direct correlation that exists between seated activity and the increased prevalence of overweight conditions (Vandelanotte, Sugiyama, Gardiner, \& Owen, 2009), challenges in regulating portion size and frequency of intake might be compounded by the widespread exposure of rural Americans to eating environments that offer unlimited meal portions for a fixed price (Wansink \& Payne, 2008).

\section{Cognitive Theories}

Individuals may lack competence for controlling desired outcomes if initial attempts to attain goals proved to be unsuccessful (Deci \& Ryan, 1985; Gormly, Gormly, \& Johnson, 1971). In addition, behavior is often determined by the prevailing attitudes and subjective norms embraced by the local culture (Ajzen, 1991; Fishbein \& Ajzen, 1975). With low socioeconomic status directly correlated to psychological wellbeing and inadequacies in health service provision (Lemieux, Saman, \& Lutfiyya, 2013), limitations in challenge persistence could mediate the decision of rural Americans to engage in health and wellness pursuits (Bandura, 1977a). Interpolating Ajzen (1991), health initiatives that promote practical planning, realistic goal setting, culturally appropriate supports, and the idea of health behavior as a self-protective tool could potentially enhance the achievement of desired health outcomes for rural Americans. 


\section{Social Psychological Theories}

Given the role of social observation as a mechanism for learning (Bandura, 1977a, 1977b), rural Americans may lack exercise motivation due to their limited exposure to prohealth role models (Festinger, 1954; Wilcox, Oberrecht, Bopp, Kammermann, \& McElmurray, 2005). For any group, the extent to which behavior is considered acceptable is often a manifestation of its social identity (Tajfel \& Turner, 1979, 1986); as such, health behavior may only be internalized if it is validated as a socially acceptable practice (Horcajo, Petty, \& Briñol, 2010). In light of Bandura's (1977b) views on social learning, (a) presumed lack of exposure to prohealth influences, and (b) continued immersion in maladaptive health perceptions might predispose rural Americans to view sedentary behavior and indiscriminate forms of eating as culturally acceptable lifestyle attributes. Pervasive fears of "overdoing it" (Wilcox et al., p. 44), concerns regarding the potential to "look stupid" (p. 44), and the belief that exercise "does more harm than it does good" (p. 45) represent perceptual barriers to the adoption of prohealth practices for many rural residents.

\section{Green Exercise: Biopsychosocial Implications}

MacKay and Neill (2010) defined green exercise as any mode of physical activity that occurs within the naturalistic setting. As an outgrowth of environmental psychology (Barker, 1968), green exercise initiatives represent the convergence of physical activity engagement and nature-based sensory immersion (Pretty et al., 2007; Pretty, Peacock, Sellens, \& Griffin, 2005). Beyond its biological impact, early research on green exercise pointed to its appreciable impact on affect regulation, stress reduction, and executive function (Ulrich, 1981). Activities such as barefoot running and forest bathing have origins in the natural setting and have been shown to positively moderate injury risk and immune function, respectively (Li, 2009; Tam, Astephenson Wilson, Noakes, \& Tucker, 2014).

Current research on walking, hiking, and running in green settings has been shown to not only heighten perceptions of connectivity with nature, but to induce degrees of energy expenditure that are comparable to nongreen activities (Wolf \& Wohlfart, 2014). Given efforts to broaden the legislative platform for ecological health initiatives (Carpenter, 2013), the global reach of green exercise is evinced in the current proliferation of green exercise partnerships worldwide, including but not limited to the Australian Conservation Foundation (2014), British Trust for Conservation Volunteers (2015), and NHS Health Scotland (2012).

\section{Self-Sufficiency, Solidarity, and Sustainability: Virtues of Social Change Agency}

The ecological implications of green exercise initiatives for rural Americans transcend the simple idea of physical activity in the naturalistic setting. Through participation in green exercise initiatives, rural residents may implicitly adopt the values of self-sufficiency, solidarity, and sustainability —each of which has wide ranging implications for positive social change.

\section{Self-Sufficiency}

Fundamentally, participation in green exercise initiatives represents opportunities to promote social interdependence (Johnson et al., 2011). Self-cohesion, self-respect, and self-determination have been cited as fundamental values of autonomy (Walter \& Friedman-Ross, 2013), which has been shown to enhance (a) self-sufficiency at the individual level and (b) group self-efficacy at the collective level (Bandura, 1977a, 1977b, 1997) As an ingroup effect (Tajfel \& Turner, 1979, 1986), the assembly of 
exercise groups in green spaces could potentially serve to (a) enhance "strength in numbers" perceptions and (b) internalize health behavior as an aspect of social identity.

By definition, self-sufficiency has implications for the progressive views that link current health practices to the welfare of future generations (Victor \& Guidry-Grimes, 2014). Given its potentially transformative impact on social perception, green exercise participation can be adopted as a social norm that is transmitted within the collective identity over the course of successive generations (Victor \& Guidry-Grimes, 2014). As a result, self-sufficiency for health behavior could be viewed as elemental to collective wellbeing.

\section{Solidarity}

Given the predictive utility of group cohesion for exercise adherence (Dunlop, Falk, \& Beauchamp, 2013), green exercise initiatives can instill a sense of community that reinforces interpersonal trust, group potentiation, and reciprocal learning (Belone et al., 2014). Here, relational bonds are strengthened as participants engage in peer observation and shared learning (Järvelä \& Järvenoja, 2011), resulting in enhanced social self-efficacy (Bandura, 1977a, 1977b, 1997). Through commitment to a common purpose, group participation could serve to enhance perceived solidarity and ingroup belonging for rural residents (Bandura, 2012; Xygalatas, Konvalinka, Roepstorff, \& Bulbulia, 2011).

When social competence is high, solidarity perceptions have been shown to have a significant influence on the adaptation capacities of the collective (Bandura, 2012). Perceived solidarity has been linked to the durability of group beliefs (Becker, 2012); such a view has implications for the malleability of health beliefs upheld by rural Americans. Solidarity, in conjunction with social identity, prosocial activity, and ingroup wellbeing, is a fundamental driver of the citizenship ideals that underpin social conscience (Condor, 2011).

\section{Sustainability}

For rural Americans, the ideals of adaptation and transformation are profoundly linked to sustainability (Brown \& Westaway, 2011; Redman, 2014). As a culturally congruent practice (Bao, Vedina, Moodie, \& Dolan, 2013), green exercise programming provides a framework for health and wellness opportunities that can yield cost effective and socially sustainable outcomes for rural Americans (Lindsey, 2011). However, negotiating the values that must be lost in order for new, more sustainable ideals to be adopted reflects a potentially precarious undertaking for rural Americans (Dodman \& Mitlin, 2013).

Presumably, maladaptive health perceptions can have negative longitudinal impacts. For rural residents, the deeply embedded social dynamics that underpin health beliefs may be in a weakened state and, thus, susceptible to socioecological transformation (Redman, 2014). As the practical utility of available health resources becomes more evident to rural residents, green exercise is more apt to be viewed a mechanism of socially sustainable outcomes. As a catalyst for a new, more sustainable health ecosystem, green exercise initiatives can engender a health behavior paradigm shift_from a means to survive toward myriad opportunities to thrive. 
Garrin, 2015

\section{The Socioecological Impact of Green Exercise: Shaping Attitudes Through Embracing Culture}

In meta-analyses of qualitative studies on the exercise attitudes of rural Americans, an inability to afford a gym membership and transportation to a fitness center were the most frequently cited obstacles to health value adoption (Wilcox et al., 2005). Countering the perception that gym memberships are essential to good health, green spaces are home to a plethora of physically demanding pursuits that not only serve to challenge physicality, but enhance awareness of the convergent value of health and nature (Gladwell, Brown, Wood, Sandercock, \& Barton, 2013). Such settings can offer a host of neuromuscular and cardiovascular health benefits, including but not limited to walking, hiking, and running (Wolf \& Wohlfart, 2014)—pursuits that have been shown to moderate blood pressure, reduce state anxiety, enhance self-concept, and improve affective status (Pretty et al., 2005; Barton \& Pretty, 2010; Mackay \& Neill, 2010).

A salient theme in green exercise discourse is the idea that program opportunities need not necessarily be "pursued," as such opportunities are essentially innate to the natural environment and, thus, readily available (Coutts, Chapin, Horner, \& Taylor, 2013). In this sense, green exercise initiatives transcend economic and geographic barriers to health behavior change-common reasons for nonadherence to exercise programming (Wilcox et al., 2005). Given exercise programming as an individualized, person-centered phenomenon (C. R. Rogers, 1961), members of a demographic group may experience highly divergent health motives, programming needs, and health self-identities (Côté, Moskowitz, \& Zuroff, 2012). As such, program participants would have the opportunity to access green exercise resources in a manner that best supports their unique needs and preferences.

Evidence shows green exercise participation to promote positive psychosocial outcomes, including but not limited to qualitative enhancements in affect, self-esteem, and subjective wellbeing (Barton, Griffin, \& Pretty, 2011; Barton \& Pretty, 2010). Perceived competence has been shown to moderate dietary choices and physical activity (Kegler, Swan, Alcantara, Feldman, \& Glanz, 2014); as such, engagement in prohealth practices can potentially instill the empowerment perceptions that underpin health self-efficacy (Tengland, 2012). Linkages between green spaces, sensory stimulation, and health status highlight the value of sensory-based learning opportunities in the adoption of prohealth practices (Duffin, 2010; Grahn \& Stigsdotter, 2010). Finally, green exercise programming has been linked to enhanced competence, motivation, autonomy, intrinsic reward, and subjective wellbeing - widely documented outcomes of exercise behavior in traditional exercise environments (Jackson, 2010; Lee \& Browne, 2008; Mata et al., 2009).

\section{Green Exercise in Rural Settings: Social, Cultural, and Economic Considerations}

Human behavior is perpetuated by timeworn ideological constellations (Shariff et al., 2014). As such, several exogenous factors could potentially impede the health behavior change process for rural Ameicans. Beard, Tomaska, Earnest, Summerhayes, and Morgan (2009) posited that socioeconomic disenfranchisement and indigenous stigma directly impact health status. Aspects of rural stoicism, maladaptive social norms, and the immigration of younger generations away from the family constellation have implications for the influence of the social schema on behavior change efforts (Beard et al., 2009). In cohorts that have internalized the avoidance of nonsurvival-oriented behaviors throughout successive generations (Adachi-Mejia et al., 2010), a deviation from habituated 
psychological and behavioral patterns may inhibit the internalization of new attitudes, values, and behaviors.

The prevalence of farming, logging, and mining in rural America could moderate the perception that exercise engagement occurs within the context of daily work (Bell, Lloyd, \& Vatovec, 2010) representing a plausible counterargument against the perceived need for green exercise participation. While the American College of Sports Medicine (2011) recommends a specified frequency, intensity, and duration of engagement in vigorous activity to prevent cardiovascular health risks, rural residents might perceive that such guidelines are to some extent adhered to within the context of daily work activity (Levine et al., 2011). As such, rural residents might believe that engagement in daily functional tasks will yield adequate levels of physical fitness and, thus, perceive engagement in structured exercise behavior as a duplication of efforts.

As an economically viable programming model, green exercise initiatives represent a cost effective means of mitigating economic stress by capitalizing on pre-existing resources (Barton \& Pretty, 2010; L. Q. Rogers, Markwell, Courneya, McAuley, \& Verhulst, 2009). However, gross socioeconomic disparities between urban and rural centers could engender perceptions of hopelessness in areas of enduring unemployment and poverty (Levine et al., 2011). With the allocation of fiscal resources considerably less likely during times of economic instability (Benedict et al., 2007; Holmes, Slifkin, Randolph, \& Poley, 2006), limitations in green exercise funding could promote the sense of economic insufficiency that many rural Americans have come to accept as an existential fact of life (Burton, Lichter, Baker, \& Eason, 2013) and consequently inhibit their motivation to adopt prohealth behaviors.

\section{Program Mentors as Agents of Social Change}

It is perhaps their ability to remain adaptable in the face of sociocultural transformation that underpins the potentiality of program mentors as agents of social change. Invoking Astin and Astin's (1996) views on social change leadership, program mentors must possess a broad understanding of the biological, psychological, and social dynamics that influence human behavior. As such, program mentors must remain committed to (a) maintaining an ongoing awareness of their evolving selfconcept and (b) self-assessing the degree of congruence between their values and their efforts to affect change (Astin \& Astin, 1996). In an effort to avoid a "one size fits all" approach to program development, program mentors must acknowledge the heterogeneous characterological composition of the groups they serve (Tajfel \& Turner, 1979, 1986). Here, it is not necessarily the program mentor's ability to shift perceptions, but his or her capacity to unconditionally embrace the individuality of the participant that is likely to engender the level of respect, trust, and community that promotes positive change (Astin \& Astin, 1996).

Communication has been cited as a key element of effective mentorship efforts (Miles, Mabey, Leggett, \& Stansfield, 2014; Steele, 2013); as such, the acceptance of participant feedback by the program mentor has inestimable value to the success of the initiative. If program mentors fail to actively listen to the needs, experiences, and perspectives of those they lead, then program implementation could be an immensely challenging endeavor. By embracing divergent views with civility and unconditional acceptance (Astin \& Astin, 1996; C. R. Rogers, 1961), mentors and participants can create a bidirectional platform for mutual collaboration and reinforce perceptions of a common purpose (Astin \& Astin, 1996). 
Further, program mentors are encouraged to acknowledge the idea that all individuals, regardless of their demographic affiliation, may experience apprehension and self-doubt when faced with the prospect of behavior change (Prochaska, Redding, et al., 2008). As a fundamental component of citizenship aptitude (Astin \& Astin, 1996), self-efficacy for behavior change can be cultivated over time with adequate support resources (Bandura, 1982, 1993). For program mentors to fully embrace the challenges of transformation, they are encouraged to conceive of change a nonsequential process that consists of progressive and regressive movements toward the adoption of new behaviors (Prochaska, Redding, et al., 2008). Just as participants enhance health self-efficacy throughout the behavior change process (Prochaska, Wright, \& Velicer, 2008), program mentors instill the citizenship aptitudes that are first potentiated at the individual level and, subsequently, generalized to the greater community (Astin \& Astin, 1996).

\section{Future Directions and Implications for Positive Social Change}

When biopsychosocial, cultural, political, and economic factors are taken into consideration, the institution of green exercise programming for rural Americans is a perhaps a viable yet formidable undertaking. As intergenerational dynamics have transmitted values, crystallized attitudes, and established socioculturally defined priorities in rural residents (Rimal, 2003), program mentors are called upon to identify, develop, and apply their potentially transformative leadership abilities. The success of green exercise initiatives resides in the capacity of mentors to (a) deconstruct archaic health ideals and (b) frame access to natural resources as a catalyst for desired health outcomes. As visionaries, program mentors must embrace self-sufficiency, solidarity, and sustainability as foundational values for collective wellbeing (Astin \& Astin, 1996). Yet, despite the appreciable psychophysiological impacts of green exercise (Barton \& Pretty, 2010; Pretty, Hine, \& Peacock, 2006), shifting attitudes, shaping values, and adopting unfamiliar lifestyle practices reflects a process that may be steeped in challenge and uncertainty for rural residents.

In their investigation of barrier underestimation for weight loss and exercise adherence, Dibonaventura and Chapman (2008) found a relatively broad gap between intention (e.g., "I want to change my behavior") and behavior (e.g., "I am changing my behavior"). Such findings evoke questions about exercise motivation and context for rural Americans: Which exogenous factors (e.g., geography, culture, residential setting) moderate the gap between exercise intentions and behavior? And to what extent do endogenous factors (e.g., self-determination, self-efficacy, self-enhancement, self-actualization) impact perceptions of exercise barrier efficacy for rural residents? As the ethnoracial landscape continues to undergo a radical shift toward greater urban-rural heterogeneity (Lichter, 2012), the sociodemographic lines between urban and rural perception continue to blur over time (Lichter \& Brown, 2011). As such, program mentors are encouraged to examine urban ideology in an effort to broaden their epistemological view of goal attainability, health self-efficacy, and challenge orientation for rural residents.

Green exercise initiatives offer viable opportunities for enhancing relationships within the greater community. As a funding model, Paddlers for Humanity (http://p4h.org/) makes practical use of green exercise environments by offering canoeing and kayaking expeditions as a means of fundraising for various nonprofit pursuits. Advancing this model, proceeds generated through green exercise initiatives could be donated to a community charity; in turn, the charity could reciprocally (a) sponsor advertising and promotion efforts for future initiatives and (b) receive community action support from program participants. After generating a groundswell, evidence of the efficacy of green exercise initiatives in rural areas could be presented to local governments (a) to obtain funding for continued programming and (b) as a mechanism for proposed legislation. Such efforts may enhance 
perceptions of self-sufficiency, solidarity, and sustainability in rural residents, and, in turn, enhanced empowerment perceptions could serve to mitigate resistance to sociocultural change (Astin \& Astin, 1996).

While promoting a state of connectivity with nature (Gladwell et al., 2013), green exercise initiatives represent opportunities for collaborative, reciprocal partnerships that facilitate mutual learning (Astin \& Astin, 1996). It is within this relational framework that both program mentors and participants become more effective learners and educators, thus broadening their platform for creative vision, coalition orientations, and continued service to the community (Astin \& Astin, 1996). Through commitment and collaboration, participants are poised to become mentors who can independently identify social problems and perhaps advance the objectives once undertaken by their predecessors (Astin \& Astin, 1996). As each season offers a unique physical challenge gradient for rural residents, the competency, empowerment, and social identity perceptions engendered by green exercise initiatives should not be viewed as a consequence of adversity or misfortune, but instead as a felicitous opportunity - to reframe timeworn views, indoctrinate prohealth ideals, and affect positive social change.

\section{References}

Adachi-Mejia, A. M., Drake, K. M., MacKenzie, T. A., Titus-Ernstoff, L., Longacre, M. R., Hendricks, K. M., ... Dalton, M. A. (2010). Perceived intrinsic barriers to physical activity among rural mothers. Journal of Women's Health, 19, 2197-2202. doi:10.1089/jwh.2009.1879

Ajzen, I. (1991). The theory of planned behavior. Organizational Behavior and Human Decision Processes, 50, 179-211.

Amedeo, M., Lundgren, L., Cohen, A., Rose, D., Chassler, D., Beltrame, C., \& D’Ippolito, M. (2011). Barriers to implementing evidence-based practices in addiction treatment programs: Comparing staff reports on motivational interviewing, adolescent community reinforcement approach, assertive community treatment, and cognitive-behavioral therapy. Evaluation and Program Planning, 34, 382-389. doi:10.1016/j.evalprogplan.2011.02.005

American College of Sports Medicine. (2011). New advice for preventing heart attacks, cardiovascular disease. Retrieved from http://www.acsm.org/about-acsm/media-room/acsmin-the-news/2011/08/01/new-advice-for-preventing-heart-attacks-cardiovascular-disease

American Heart Association. (2014). Heart and stroke statistics. Retrieved from http://www.heart.org/HEARTORG/General/Heart-and-Stroke-AssociationStatistics_UCM_319064_SubHomePage.jsp

Astin, H. S., \& Astin, A. W. (1996). A social change model of leadership development: Guidebook (version 3). Los Angeles, CA: Higher Education Research Institute, University of California, Los Angeles.

Australian Conservation Foundation. (2014). Ten reasons why we need more contact with nature. Retrieved from http://www.acfonline.org.au/news-media/news-features/ten-reasons-why-weneed-more-contact-nature

Bandura, A. (1977a). Self-efficacy: Toward a unifying theory of behavioral change. Psychological Review, 84, 191-215.

Bandura, A. (1977b). Social learning theory. New York, NY: General Learning Press.

Bandura, A. (1982). Self-efficacy mechanism in human agency. American Psychologist, 37, 122-147. 
Bandura, A. (1993). Perceived self-efficacy in cognitive development and functioning. Educational Psychologist, 28, 117-148.

Bandura, A. (1997). Self-efficacy: The exercise of control. New York, NY: W.H. Freeman.

Bandura, A. (2012). On the functional properties of perceived self-efficacy revisited. Journal of Management, 38, 9-44. doi:10.1177/0149206311410606

Bao, Y., Vedina, R., Moodie, S., \& Dolan, S. (2013). The relationship between value incongruence and individual and organizational well-being outcomes: An exploratory study among Catalan nurses. Journal of Advanced Nursing, 69, 631-641. doi:10.1111/j.1365-2648.2012.06045.x

Barker, R. G. (1968). Ecological psychology: Concepts and methods for studying the environment of human behavior. Stanford, CA: Stanford University Press.

Barton, J., Griffin, M., \& Pretty, J. (2011). Exercise-, nature- and socially interactive-based initiatives improve mood and self-esteem in the clinical population. Perspectives in Public Health, 132, 89-96. doi:10.1177/1757913910393862

Barton, J., \& Pretty, J. (2010). What is the best dose of nature and green exercise for improving mental health? A multi-study analysis. Environmental Science \& Technology, 44, 3947-3955. doi:10.1021/es903183r

Beard, J., Tomaska, N., Earnest, A., Summerhayes, R., \& Morgan, G. (2009). Influence of socioeconomic and cultural factors on rural health. Australian Journal of Rural Health, 17, 10-15. doi:10.1111/j.1440-1584.2008.01030.x

Becker, J. C. (2012). Virtual special issue on theory and research on collective action in the European Journal of Social Psychology. European Journal of Social Psychology, 42, 19-23. doi:10.1002/ejsp.1839

Bell, M. M., Lloyd, S. E., \& Vatovec, C. (2010). Activating the countryside: Rural power, the power of the rural and the making of rural politics. Sociologia Ruralis, 50, 205-224. doi:10.1111/j.1467-9523.2010.00512.x

Belone, L., Lucero, J. E., Duran, B., Tafoya, G., Baker, E. A., Chan, D., Chang, C., ... Wallerstein, N. (2014). Community-based participatory research conceptual model: Community partner consultation and face validity. Qualitative Health Research. Advance online publication. doi:10.1177/1049732314557084

Benedict, S., Campbell, M., Doolen, A., Rivera, I., Negussie, T., \& Turner-McGrievy, G. (2007). Seeds of hope: A model for addressing social and economic determinants of health in a women's obesity prevention project in two rural communities. Journal of Women's Health, 16, 11171124 .

British Trust for Conservation Volunteers. (2015). TVC created and runs green gyms across the U.K. Retrieved from http://www.tcv.org.uk/greengym

Brown, K., \& Westaway, E. (2011). Agency, capacity and resilience to environmental change: Lessons from human development. Annual Review of Environment and Resources, 36, 321-342.

Burton, L. M., Lichter, D. T., Baker, R. S., \& Eason, J. M. (2013). Inequality, family processes, and health in the "new" rural America. American Behavioral Scientist, 57, 1128-1151. doi:10.1177/0002764213487348 
Carpenter, M. (2013). From "healthful exercise" to "nature on prescription": The politics of urban green spaces and walking for health. Landscape and Urban Planning, 118, 120-127. doi:10.1016/j.landurbplan.2013.02.009

Centers for Disease Control and Prevention (CDC). (2013a). Overweight and obesity. Obesity prevalence maps. Retrieved from http://www.cdc.gov/obesity/data/prevalence-maps.html

Centers for Disease Control and Prevention (CDC). (2013b). Workplace health promotion. Rising health care costs are unsustainable. Retrieved from http://www.cdc.gov/workplacehealthpromotion/businesscase/reasons/rising.html

Condor, S. (2011). Towards a social psychology of citizenship? Introduction to the special issue. Journal of Community \& Applied Psychology, 21, 193-201. doi:10.1002/casp.1089

Côté, S., Moskowitz, D. S., \& Zuroff, D. C. (2012). Social relationships and intraindividual variability in interpersonal behavior: Correlates of interpersonal spin. Journal of Personality and Social Psychology, 102, 646-659. doi:10.1037/a0025313

Coutts, C., Chapin, T., Horner, M., \& Taylor, C. (2013). The county-level effects of green space access on physical activity. Journal of Physical Activity and Health, 10, 232-240.

Dabney, J. (1964). Energy balance and obesity. Annals of Internal Medicine, 60, 689-699.

Deci, E. L., \& Ryan, R. M. (1985). Intrinsic motivation and self-determination in human behavior. New York, NY: Plenum.

Dibonaventura, M., \& Chapman, G. B. (2008). The effect of barrier underestimation on weight management and exercise change. Psychology, Health \& Medicine, 13, 111-122. doi:10.1080/13548500701426711

Dickson, V. V., McCarthy, M. M., Howe, A., Schipper, J., \& Katz, S. M. (2013). Sociocultural influences on heart failure self-care among an ethnic minority black population. Journal of Cardiovascular Nursing, 28, 111-118. doi:10.1097/JCN.0b013e31823db328

Dodman, D., \& Mitlin, D. (2013). Challenges for community-based adaptation: Discovering the potential for transformation. Journal of International Development, 25, 640-659. doi:10.1002/jid.1772

Duffin, C. (2010). Teaching people the benefits of a healthy diet and exercise. Learning Disability Practice, 13, 12-16. doi:10.7748/ldp2010.02.12.1.12c7539

Dunlop, W. L., Falk, C., \& Beauchamp, M. R. (2013). How dynamic are exercise group dynamics? Examining changes in cohesion within class-based exercise programs. Health Psychology, 32, 1240-1243. doi:10.1037/a0030412

Durkheim, E. (1924). Sociology and philosophy. New York, NY: The Free Press.

Engstrom, L. (2004). Social change and physical activity. Scandinavian Journal of Nutrition, 48, 108-113. doi:10.1080/16513860410017674

Festinger, L. (1954). A theory of social comparison processes. Human Relations, 7, 117-140.

Finkelstein, E. A., Trogdon, J. G., Cohen, J. W., \& Dietz, W. (2009). Annual medical spending attributable to obesity: Payer and service specific estimates. Health Affairs, 28, 822-831.

Fishbein, M., \& Ajzen, I. (1975). Belief, attitude, intention, and behavior: An introduction to theory and research. Reading, MA: Addison-Wesley. 
Gladwell, V. F., Brown, D. K., Wood, C., Sandercock, G. R., \& Barton, J. L. (2013). The great outdoors: How a green exercise environment can benefit all. Extreme Physiology \& Medicine, 2, 3-10. doi:10.1186/2046-7648-2-3

Gormly, J., Gormly, A., \& Johnson, C. (1971). Interpersonal attraction: Competence motivation and reinforcement theory. Journal of Personality \& Social Psychology, 19, 375-380.

Grahn, P., \& Stigsdotter, U. K. (2010). The relation between perceived sensory dimensions of urban green space and stress restoration. Landscape and Urban Planning, 94, 264-275. doi:10.1016/j.landurbplan.2009.10.012

Holmes, G. M., Slifkin, R. T., Randolph, R. K., \& Poley, S. (2006). The effect of rural hospital closures on community economic health. Health Services Research, 41, 467-485. doi:10.1111/j.14756773.2005.00497.x

Horcajo, J., Petty, R. E., \& Briñol, P. (2010). The effects of majority versus minority source status on persuasion: A self-validation analysis. Journal of Personality and Social Psychology, 99, 498512. doi:10.1037/a0018626

Jackson, D. (2010). How personal trainers can use self-efficacy theory to enhance exercise behavior in beginning exercisers. Strength \& Conditioning Journal, 32, 67-71.

Järvelä, S., \& Järvenoja, H. (2011). Socially constructed self-regulated learning and motivation regulation in collaborative learning groups. Teachers College Record, 113, 350-374.

Johnson, M., Bradshaw, J. M., Feltovich, P. J., Jonker, C. M., Riemsdijk, B., \& Sierhuis, M. (2011). The fundamental principle of coactive design: Interdependence must shape autonomy. Coordination, Organizations, Institutions, and Norms in Agent Systems, 65, 172-191. doi:10.1007/978-3-642-21268-0_10

Kalivas, P. W. (2003). Predisposition to addiction: Pharmacokinetics, pharmacodynamics, and brain circuitry. The American Journal of Psychiatry, 160, 1-2. doi:10.1176/appi.ajp.160.1.1

Kegler, M. C., Swan, D. W., Alcantara, I., Feldman, L., \& Glanz, K. (2014). The influence of rural home and neighborhood environments on healthy eating, physical activity, and weight. Prevention Science, 15, 1-11. doi:10.1007/s11121-012-0349-3

Lee, A., \& Browne, M. (2008). Subjective well-being, sociodemographic factors, mental and physical health of rural residents. Australian Journal of Rural Health, 16(5), 290-296.

Lemieux, A., Saman, D., \& Lutfiyya, M. N. (2013). Population-based study of health service deficits in U.S. adults with depression: Does chronic disease co-morbidity and/or rural residency make a difference? Scientific Research, 5, 774-782. doi:10.4236/health.2013.54103

Levine, J. A., McCrady, S. K., Boyne, S., Smith, J., Cargill, K., \& Forrester, T. (2011). Non-exercise physical activity in agricultural and urban people. Urban Studies, 48, 2417-2427. doi:10.1177/0042098010379273

Li, Q. (2009). Effect of forest bathing trips on human immune function. Environmental Health and Preventive Medicine, 15, 9-17. doi:10.1007/s12199-008-0068-3

Lichter, D. T. (2012). Immigration and the new racial diversity in rural America. Rural Sociology, 77, 3-35. doi:10.1111/j.1549-0831.2012.00070.x

Lichter, D. T., \& Brown, D. L. (2011). Rural America in an urban society: Changing spatial and social boundaries. Annual Review of Sociology, 37, 565-592. 
Lindsey, T. C. (2011). Sustainable principles: Common values for achieving sustainability. Journal of Cleaner Production, 19, 561-565.

Liu, Y., von Deneen, K. M., Kobeissy, F. H., \& Gold, M. S. (2010). Food addiction and obesity: Evidence from bench to bedside. Journal of Psychoactive Drugs, 42, 133-145.

Logan, H., Guo, Y., Dodd, V. J., Muller, K., \& Riley, J. (2013). The burden of chronic diseases in a rural north Florida sample. BMC Public Health, 13, 906. doi:10.1186/1471-2458-13-906

Lutfiyya, M., Chang, L., \& Lipsky, M. (2012). A cross-sectional study of U.S. rural adults' consumption of fruits and vegetables: Do they consume at least five servings daily? $B M C$ Public Health, 12, 280. doi:10.1186/1471-2458-12-280

Lutfiyya, M. N., McCullough, J. E., Saman, D. M., Lemieux, A., Hendrickson, S., McGrath, C. A., ... Lipsky, M. S.. (2013). Rural/urban differences in health services deficits among U.S. adults with arthritis: A population-based study. Journal of Nursing Education and Practice, 3, 4353. doi:10.5430/jnep.v3n11p43

Mackay, G. J. S., \& Neill, J. T. (2010). The effect of "green exercise" on state anxiety and the role of exercise duration, intensity, and greenness: A quasi-experimental study. Psychology of Sport and Exercise, 11, 238-245. doi:10.1016/j.psychsport.2010.01.002

Mata, J., Silva, M. N., Vieira, P. N., Carraça, E. V., Andrade, A. M., Coutinho, S. R., ... Teixeira, P. J. (2009). Motivational "spill-over" during weight control: Increased self-determination and exercise intrinsic motivation predict eating self-regulation. Health Psychology, 28, 709-716. doi:10.1037/a0016764

Miles, L. W., Mabey, L., Leggett, S., \& Stansfield, K. (2014). Teaching communication and therapeutic relationship skills to baccalaureate nursing students: A peer mentorship simulation approach. Journal of Psychosocial Nursing and Mental Health Services, 52, 3441. doi:10.3928/02793695-20140829-01

NHS Health Scotland. (2012, June 4). A fairer healthier Scotland: Our strategy 2012-2017. Edinburgh, Scotland: Author. Retrieved from http://www.healthscotland.com/uploads/documents/5792-CorporateStrategy.pdf

Ogden, C. L., Carroll, M. D., Kit, B. K., \& Flegal, K. M. (2014). Prevalence of childhood and adult obesity in the United States, 2011-2012. Journal of the American Medical Association, 311, 806-814. doi:10.1001/jama.2014.732

Orford, J. (1985). Excessive appetites: A psychological view of addictions. Chichester, England: Wiley.

Orford, J., Morison, V., \& Somers, M. (1996). Drinking and gambling: A comparison with implications for theories of addiction. Drug and Alcohol Review, 15, 47-56.

Owen, N., Sparling, P. B., Healy, G. N., Dunstan, D. W., \& Matthews, C. E. (2010). Sedentary behavior: Emerging evidence for a new health risk. Mayo Clinic Proceedings, 85, 11381141. doi:10.4065/mcp.2010.0444

Parsons, T. (1966). Societies: Evolutionary and comparative perspectives. Engelwood Cliffs, NJ: Prentice-Hall.

Pretty, J., Hine, R., \& Peacock, J. (2006). Green exercise: The benefits of activities in green places. Biologist, 53, 143-148.

Pretty, J., Peacock, J., Hine, R., Sellens, M., South, N., \& Griffin, M. (2007). Green exercise in the U.K. countryside: Effects on health and psychological well-being, and implications for policy 
and planning. Journal of Environmental Planning and Management, 50, 211-231. doi:10.1080/09640560601156466

Pretty, J., Peacock, J., Sellens, M., \& Griffin, M. (2005). The mental and physical health outcomes of green exercise. International Journal of Environmental Health Research, 15, 319-337. doi:10.1080/09603120500155963

Prochaska, J., O., Redding, C. A., \& Evers, K. E. (2008). The transtheoretical model and stages of change. Health behavior and health education: Theory, research, and practice (4th ed., pp. 97-121). San Francisco, CA: Jossey-Bass.

Prochaska, J. O., Wright, J. A., \& Velicer, W. F. (2008). Evaluating theories of health behavior change: A hierarchy of criteria applied to the transtheroetical model. Applied Psychology: An International Review, 57, 561-588.

Redman, C. L. (2014). Should sustainability and resilience be combined or remain distinct pursuits? Ecology and Society, 19, 37. doi:10.5751/ES-06390-190237

Rimal, R. N. (2003). Intergenerational transmission of health: The role of intrapersonal, interpersonal, and communicative factors. Health Education \& Behavior, 30, 10-28. doi:10.1177/1090198102239256

Rogers, C. R. (1961). On becoming a person: A therapist's view of psychotherapy. London, U.K: Constable.

Rogers, L. Q., Markwell, S. J., Courneya, K. S., McAuley, E., \& Verhulst, S. (2009). Exercise preference patterns, resources, and environment among rural breast cancer survivors. The Journal of Rural Health, 25, 388-391. doi:10.1111/j.1748-0361.2009.00249.x

Rosenstock, I. M., Strecher, V. J., \& Becker, M. H. (1988). Social learning theory and the health belief model. Health Education \& Behavior, 15, 175-183. doi:10.1177/109019818801500203

Santulli, G. (2013). Epidemiology of cardiovascular disease in the 21st century: Updated numbers and updated facts. Journal of Cardiovascular Disease, 1, 1-2.

Shariff, A. F., Greene, J. D., Karremans, J. C., Luguri, J. B., Clark, C. J., Schooler, J. W., ... Vohs, K. D. (2014). Free will and punishment: A mechanistic view of human nature reduces retribution. Psychological Science, 1, 1-8. doi:10.1177/0956797614534693

Springer, J. B., Lamborn, S. D., \& Pollard, D. M. (2013). Maintaining physical activity over time: The importance of basic psychological need satisfaction in developing the physically active self. American Journal of Health Promotion, 27, 284-293. doi:10.4278/ajhp.110211-QUAL-62

Steele, R. G. (2013). The social construction of professional mentorship. Journal of Pediatric Psychology, 38, 126-131. doi:10.1093/jpepsy/jss177

Tajfel, H., \& Turner, J. C. (1979). An integrative theory of intergroup conflict. In W.G. Austin \& S. Worchel (Eds.), The social psychology of intergroup relations (pp. 94-109). Monterey, CA: Brooks-Cole.

Tajfel, H., \& Turner, J. C. (1986). The social identity theory of inter-group behavior. In S. Worchel \& L. W. Austin (Eds.), Psychology of intergroup relations. Chicago, IL: Nelson-Hall.

Tam, N., Astephenson Wilson, J. L., Noakes, T. D., \& Tucker, R. (2014). Barefoot running: An evaluation of current hypothesis, future research and clinical applications. British Journal of Sports Medicine, 48, 349-355. doi:10.1136/bjsports-2013-092404 
Tengland, P. A. (2012). Behavior change or empowerment: On the ethics of health-promotion strategies. Public Health Ethics, 5, 140-153.

Thorp, A. A., Owen, N., Neuhaus, M., \& Dunstan, D. (2011). Sedentary behaviors and subsequent health outcomes in adults. American Journal of Preventative Medicine, 41, 207-215. doi:10.1016/j.amepre.2011.05.004

Ulrich, R. S. (1981). Natural versus urban scenes: Some psychophysiological effects. Environment and Behavior, 13, 523-556. doi:10.1177/0013916581135001

Vandelanotte, C., Sugiyama, T., Gardiner, P., \& Owen, N. (2009). Associations of leisure-time internet and computer use with overweight and obesity, physical activity and sedentary behaviors: Cross-sectional study. Journal of Medical Internet Research, 11, e28.

Victor, E., \& Guidry-Grimes, L. (2014). The persistence of agency through social institutions and caring for future generations. International Journal of Feminist Approaches to Bioethics, 7, $122-141$.

Walter, J. K., \& Friedman-Ross, L. (2013). A non-paternalistic conception of relational autonomy still needs others. Philosophy, Psychiatry, \& Psychology, 20, 187-189. doi:10.1353/ppp.2013.0020

Wansink, B., \& Payne, C. R. (2008). Eating behavior and obesity at Chinese buffets. Obesity, 16, 1957-1960. doi:10.1038/oby.2008.286

Wilcox, S., Oberrecht, L., Bopp, M., Kammermann, S. K., \& McElmurray, C. T. (2005). A qualitative study of exercise in older African American and white women in rural South Carolina: Perceptions, barriers, and motivations. Journal of Women \& Aging, 17, 37-53. doi:10.1300/J074v17n01_04

Wolf, I. D., \& Wohlfart, T. (2014). Walking, hiking and running in parks: A multidisciplinary assessment of health and well-being benefits. Landscape and Urban Planning, 130, 89-103. doi:10.1016/j.landurbplan.2014.06.006

World Health Organization (WHO). (2014). Obesity and overweight [Fact sheet]. Retrieved from http://www.who.int/mediacentre/factsheets/fs311/en/

Xygalatas, D., Konvalinka, I., Roepstorff, A., \& Bulbulia, J. (2011). Quantifying collective effervescence: Heart-rate dynamics at a fire-walking ritual. Communicative \& Integrative Biology, 4, 735-738.

The Journal of Social Change, sponsored by Walden University, welcomes manuscripts focusing on interdisciplinary research in social change that improves the human condition and moves people, groups, organizations, cultures, and society toward a more positive future.

Walden University Publishing: http://www.publishing.waldenu.edu 